\title{
Company Size and the Decentralization of Manufacturing
}

\author{
Joseph Persky \\ and \\ Ronald Moses*
}

The process of industrial decentralization in the United States has been the subject of much research. ${ }^{1}$ Recently several scholars have become concerned with the role of large corporations in the ongoing regional shift of manufacturing production. ${ }^{2}$ Several of these have drawn the analogy to the spread of multi-national corporations abroad. This growing literature suggests that large corporations are a driving force of industrial decentralization within the U.S. Given the absolute importance of large corporations in the American economy, it would be hard to imagine that they have not participated in this movement. However there is little evidence as to whether the decentralization of these large corporations has been disproportionate in any important sense. The purpose of this paper is to determine whether significant disproportionality is in evidence.

Presumably, large corporations are able to provide internally inputs which smaller firms must either buy in the market or obtain as the externalities of other firms. The large corporation comes to a peripheral location with an internal labor market including well defined training programs, the capacity to mobilize internal finance, established contacts with final markets, the logistical ability to maintain sources of supply, and a sophistication in dealing with government officials. ${ }^{3}$ Recently this view has been supplemented by the notion of the product-cycle as advanced by Raymond Vernon. ${ }^{4}$ Presumably firms with well-established products at the "mature" stage of the cycle are more likely to be concerned with the price of unskilled labor and less likely to be dependent on the externalities of established areas. Thus large corporations with "mature" products may be footloose for two broad sets of reasons: 1) their well established products make them less dependent on the complex of externalities provided in established central locations and 2) their scale allows them to substitute internal economies for external ones.

This characterization of the nature of large scale firms suggests arguments vis-a-vis the ongoing decentralization of manufacturing in the United States. The historically high concentration of industrial activity in the manufacturing belt has often been offered as proof of the importance of agglomerative

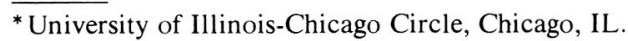


economies holding firms in this area. Clearly a modern large corporation capable of sustaining production thousands of miles from its home base should not find much difficulty in expanding production in less industrialized areas of the United States, i.e., the South and the West. If other aspects of the location decision (wages, resources, markets, etc.) point toward these formerly peripheral regions, large corporations should have a relative advantage in exploiting such opportunities. Again the logic here is that large corporations have found relatively efficient ways to release themselves from dependence on established markets and industrial environments.

The above arguments are derived directly or indirectly from the literature on the spread of multinational corporations. The clear tendency toward decentralization of manufacturing in the U.S. has prompted a search for precedents. Moreover it is obvious that large corporations have participated in this process. Nevertheless analogies can often be deceiving. First the U.S. regions outside the manufacturing belt have far more infrastructure than less developed countries. While those regions may still present considerable locational difficulties to smaller operations heavily dependent on their environment, many small firms which would not be able to operate in less developed countries may find the environments of the South and the West quite tolerable. Especially in the period since World War II, transportation and communication facilities have greatly enhanced the ability of even small firms to participate in distant markets and to enjoy from afar at least some of the externalities created by large metropolitan areas. Similarly, financing and government assistance for smaller firms are much more readily available in even the peripheral regions of an industrialized country than in the third world.

Under these circumstances there must be some doubt about the relevance of the multinational model to the U.S. case. Studies of decentralization in other industrialized countries show varying patterns with respect to the involvement of large corporations. ${ }^{5}$ What follows is an attempt to use industry data to determine the importance of company size in the post World War II decentralization of manufacturing industries in the United States. While ideally we would want information on specific corporations and their establishments, such micro-data is notoriously difficult to obtain. ${ }^{6}$ On the other hand it is not difficult to obtain data on the size of firms within different industries. Under these circumstances, we will focus on the differences in the pace of decentralization between industries with large firms and those with smaller companies. This approach demands that we also consider other industry characteristics that would be expected to influence the rate of decentralization.

The first section of the paper describes the industries analyzed. The second section presents simple tests of the hypothesis that industries dominated by large corporations have decentralized faster than those made up of smaller firms. The third section extends this testing to consider interactions between company size and other important determinants of decentralization. To briefly anticipate our results, we find no evidence that industries dominated by large corporations have been leaders in the decentralization of U.S. 
manufacturing. Indeed, it seems that such industries have been significantly slower to disperse from the manufacturing belt. The last section summarizes these findings and suggests theoretical rationalizations.

\section{INDUSTRIES AND COMPANY SIZE}

The data used in this paper is drawn from the Census of Manufactures for 1947 and $1972 .{ }^{7}$ Given our interest in the importance of company size, the first step in organizing the data was to establish a mechanism to categorize industries. One possibility was to use average company size. This approach has serious shortcomings since a large number of relatively small companies can seriously distort such a variable. To avoid this problem we decided to use the four-firm concentration ratios in combination with the industry's size (value added) to estimate an average size for the top four firms. Working from such a variable, the question of establishing a cut-off point to define "large" is of course somewhat arbitrary. The empirical work reported below uses a 1958 value added of $\$ 25$ million per firm. Exercises in sensitivity analysis suggest that modest alterations in this figure do not result in instability. For the remainder of this paper, then, industries in which the top four firms averaged more than $\$ 25$ million in value added will be referred to as Type I industries. Industries with smaller top firms will be called Type II. ${ }^{8}$

The basic data for this study is a random sample of four-digit SIC-Code manufacturing industries. However the original sample did not yield a large number of Type I industries. Thus it was supplemented with an oversampling of industries that met the Type I criterion. Since the focus here is industry decentralization, it was necessary to exclude all those four-digit industries for which there was not consistent data in 1947 and 1972. This means that industries that were not separately established in 1947 have been excluded from the sample. Thus an important word of caution is in order. It has been suggested by several regional economists that new industries have played an important role in the emergence of the South and the West. Petro-chemicals and aerospace industries are the two most often mentioned in this respect. We suspect that the location patterns of new industries both of Type I and of Type II are significantly different from those of well established industries. This is a matter that deserves attention in its own right. However the approach taken here does not allow consideration of such phenomena. Therefore, the results apply only to the post-war decentralization of industries with well defined location patterns at the beginning of that period.

Appendix I contains a list of the four-digit industries included in the Type I and the Type II samples. The former consists of 31 industries and the latter of 41. To get some feel for the two groups, Table I presents summary information on their characteristics. Here it is clear that Type I industries not only had larger top firms than those in Type II, but also tended to have higher concentration ratios, earnings per employee, plant size and growth rates. The table also shows that the Type I industries had somewhat smaller wage shares in 
TABLE I

Characteristics of Type I and Type II Industries*

\begin{tabular}{lccr}
\hline & & Type I & Type II \\
\hline Real Growth 1948-1972** & Mean & $145 \%$ & $93 \%$ \\
& S.D. & $151 \%$ & $119 \%$ \\
Annual & Mean & $\$ 5,381$ & $\$ 4,371$ \\
Earnings/Employee, 1958 & S.D. & $\$ 613$ & $\$ 893$ \\
Wage Share of Value Added, 1958 & Mean & $43 \%$ & $55 \%$ \\
& S.D. & $14 \%$ & $10 \%$ \\
4-Firm Concentration Ratio, 1958 & Mean & $56 \%$ & $36 \%$ \\
& S.D. & $16 \%$ & $18 \%$ \\
Value Added/Plant, 1958 & Mean & $\$ 3.57$ & 0.73 \\
$\quad$ \$ millions/plant) & S.D. & $\$ 4.06$ & 0.90 \\
Water Use/Value Added & Mean & 0.12 & 0.03 \\
$\quad$ ('000's of gallons/\$ value added) & S.D. & 0.32 & 0.06 \\
\hline
\end{tabular}

* Type I industries are those in which the top four firms average value added in 1958 was greater than $\$ 25$ million. For Type II industries the average was less than $\$ 25$ million.

** 1948 value added for all industries was deflated by the implicit GNP price deflator.

value added. None of these findings runs particularly counter to intuition. However they do suggest that in evaluating the regional decentralization patterns of the two groups of industries we should be careful to control for these types of differences, differences likely to influence mobility in their own right.

\section{THE PACE OF DECENTRALIZATION}

As suggested above our basic interest is the decentralization of Type I and Type II industries from the manufacturing belt. For this paper the manufacturing belt is defined as simply the sum of the Census' Northeast and North Central regions. The South and the West then make up the rest of the country. Table II presents summary data for these two broad areas in 1947 and 1972. The table includes shares of U.S. population, personal income and manufacturing value added. The regional distributions of value added originating in Type I and Type II industries are also given.

Type I industries have been somewhat more concentrated than Type II industries in the manufacturing belt. On average $78 \%$ of the former and about $74 \%$ of the latter were located in the North in 1947 . The second observation to make from Table II is that the North's average share of Type I industries was more stable than its declining average share of Type II industries. This result is particularly striking when viewed relative to changing population shares. Here we see that the average Type I location quotient falls ten points from 1.42 to 1.32 while the average Type II location quotient falls twenty-two points from 1.34 to 1.12 . 
TABLE II

Regional Distribution of Manufacturing Value Added for Type I and Type II Industries

$1947 \& 1972$

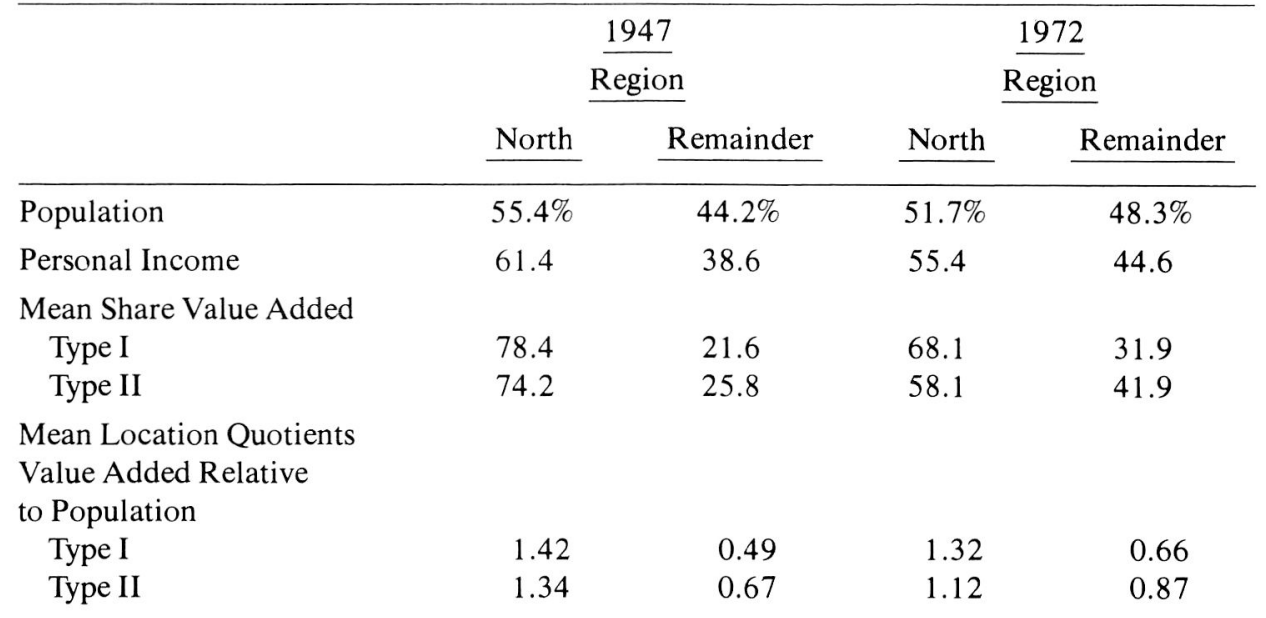

Change in Remainder Share

1947-1972

$\begin{array}{ccr}\text { Type I } & \text { Mean. } & 10.3 \% \\ & \text { S.D. } & 8.6 \% \\ \text { Type II } & \text { Mean } & 16.0 \% \\ & \text { S.D. } & 13.8 \%\end{array}$

The impression left by these statistics is that Type I industries, far from being more prone to decentralization than Type II industries, were actually less likely to shift out of the manufacturing belt. A simple test of this proposition is to compare the average change in shares between the two groups. Here an increase in the share of the South and the West is represented by a positive sign. Change in share is the basic measure of decentralization. These average values as well as their standard deviations for the two groups of industries are included at the bottom of Table II. The first hypothesis is that the mean changes in shares were the same for both groups. A significant t-statistic here of 2.4 suggests that the two groups do indeed have different mean changes for the period in question. The industries dominated by large corporations shifted away from the manufacturing belt at a slower rate.

It should be noted that the variances of change of shares within the two groups of industries are not equal. In particular, Type II industries seem to 
have considerably higher variances around their higher mean. Thus industries dominated by large corporations are more similar in their decentralization pattern than those with smaller firms. This greater degree of homogeneity could conceivably reflect a generally higher level of similarity among the Type I industries than among the Type II industries. However, the standard deviations given in Table I do not strongly support such a hypothesis. ${ }^{9}$

Our results are particularly surprising since the Type I industries start with a more concentrated base in the manufacturing belt. Thus the Type II industries have started with a higher share outside the North and increased that share faster than the Type I industries. All this occurs with a slower growth rate.

\section{THE DETERMINANTS OF DECENTRALIZATION}

In this section we will explore the relationship between the rate of decentralization and industry characteristics. It has already been noted in Table II that Type I and Type II industries differ substantially in their average values for location-relevant variables. Moreover there is reason to suspect the presence of significant interaction effects between these variables and company size. The formal statistical analysis presented below uses an analysis of covariance to compare decentralization equations estimated separately for the two groups of industries.

The first major variable included in the analysis is annual earnings per employee. The basic expectation here is that low wage industries are less concerned with labor quality and can more easily adapt to areas without the skilled industrial labor force of the North. Furthermore a negative relation of decentralization with this variable is expected. If Type I industries can draw on internal labor markets, this variable should be much less important for these industries.

The wage share of value added is also included in the analysis. This variable is meant to capture the sensitivity of labor intensive industries to average wage differentials between the manufacturing belt and the South. Presumably this variable would be a motivation to movement for both Type I and Type II industries.

Earlier work on decentralization emphasized the importance of industry concentration ratios. Fuchs found a considerable role for this variable and suggests a strong tendency for highly concentrated firms to decentralize [Fuchs, 1961]. There is little theory to support this effect. If anything, one might expect highly oligopolistic firms to have a good deal of inertia. The concentration variable (four-firm concentration ratio) is included here to provide a retest of Fuchs' findings in this context.

The fourth characteristic considered is the industry growth rate. Other things being equal, more rapidly growing industries would tend to decentralize faster if the desired regional share is more decentralized than the actual share. It is easier to direct new activity toward the periphery than redirect ex- 
TABLE III

Regression Equations for Decentralization by Type of Industry

(1) Type I Industries

$\mathrm{R}^{2}=0.32 \quad$ S.E. $=0.086 \quad \mathrm{~N}=31$

Variable

Constant

Real Growth 1948-1972

Annual Earnings/Employee

Earnings Share of Value Added

4-Firm Concentration Ratio

Value Added/Plant, 1958

Water Use/Value Added

(2) Type II Industry

$$
\mathrm{R}^{2}=0.34 \quad \text { S.E. }=0.138 \quad \mathrm{~N}=41
$$

$\underline{\text { Variable }}$

Constant

Real Growth, 1948-1972

Annual Earnings/Employee

Earnings Share of Value Added

4-Firm Concentration Ratio

Value Added/Plant 1958

Water Use/Value Added
Coefficient

$-.172$

.004

.015

.287

.0014

$-.007$

.097

$\begin{array}{cc}\text { Coefficient } & \text { Standard Error } \\ .681 & .181 \\ .042 & .018 \\ -.082 & .023 \\ -.278 & .232 \\ -.0019 & .001 \\ .036 & .026 \\ -.320 & .330\end{array}$

\begin{tabular}{c} 
Standard Error \\
\hline .144 \\
.010 \\
.028 \\
.112 \\
.001 \\
-.005 \\
.053
\end{tabular}

.330

(3) Pooled (Type I \& Type II Industries Combined)

$$
\mathrm{R}^{2}=0.19 \quad \text { S.E. }=0.121 \quad \mathrm{~N}=72
$$

\section{Variable}

Constant

Real Growth, 1948-1972

Annual Earnings/Employee

Earnings Share of Value Added

4-Firm Concentration Ratio

Value Added/Plant, 1958

Water Use/Value Added

$\begin{array}{cc}\begin{array}{cc}\text { Coefficient } \\ .260\end{array} & \text { Standard Error } \\ .018 & .111 \\ .052 & .010 \\ .189 & .018 \\ .000 & .117 \\ .002 & .001 \\ .074 & .006 \\ \end{array}$

isting output. Clearly growth should be more important to that industry which has a stronger desire to move. In terms of the basic regression model employed below this can be interpreted as the hypothesis that the coefficient for the growth variable should be greater for whichever industry group has the higher intercept term.

It has been suggested by several researchers that large plant size is a spur to decentralization. In particular, industries with large plants might see the South and the West as attractive for expansion since obtaining large locations in 
these regions would often be cheaper and easier. The logic here reflects the often suggested (but seldom substantiated) analogy between intrametropolitan suburbanization and inter-regional decentralization. Presumably this argument is more important for the Type I industries where large plants are more common than for the Type II industries where plant size is much more modest. Plant size is measured in terms of millions of dollars of value added per plant.

Along a similar line several regional economists and economic geographers have argued that substantial requirements for water resources have directed industries away from the manufacturing belt. ${ }^{10}$ This variable hopefully captures the need of absolutely large quantities of water in an industry. Again this variable would be more likely to reach high values for Type I industries. To capture such an effect a measure of large scale water usage is included. It is defined as thousands of gallons per dollar of value added.

Industry growth rates were computed for the years 1947-1972 using a GNP price deflator. All the other variables described above are computed for 1958 close to the midpoint of the period. These data are from the Census of Manufactures for that year. For each of the two groups of industries, the change in manufacturing belt shares between 1947 and 1972 was regressed on this set of six variables. A pooled equation was also estimated. The three resulting sets of coefficients are presented in Table III. The first hypothesis is that the Type I sample and the Type II sample are drawn from the same population, i.e. that their equations are identical. To do this we use covariance analysis which tests whether the separately estimated equations fit the data points significantly better than the pooled equation. ${ }^{11}$ The $\mathrm{F}$ value for this test is 2.46 , and is significant at the 5\% level. This difference is by no means limited to the intercept term. If we compare the equations for Type I and Type II industries to a pooled equation with a dummy variable for industry type, but no other interaction terms, we still find a significant difference at the 5\% level. This implies that at least some of the independent variables interact with industry type.

Perhaps the most straightforward result is the apparent insensitivity of Type I industries to their wage rates. While the high wage Type II industries are reluctant to decentralize and their low wage cousins seem eager, the Type I industries show only a negligible positive effect of wage rates on mobility. This finding is in keeping with our hypotheses. It is certainly not news that lower wage industries have been attracted away from the manufacturing belt. However, the finding, that in industries dominated by large corporations like the Type I sample the wage rate and presumably the skill mix has little effect on mobility characteristics, lends support to the position that internal labor markets free such industries from dependence on external sources of skilled labor.

Lest the above result be interpreted as suggesting that the Type I industries are just less sensitive to labor costs, it is instructive to note that it is this group 
which shows the larger coefficient on the wage share variable. For the Type I industries this variable is clearly the most important of the six included here. For the Type II industries the wage share variable shows a weak unexpected negative sign (higher wage shares being associated with lower rates of decentralization).

The growth rate variable has the expected effect for the Type II industries, suggesting that rapidly growing industries are more likely to decentralize. For the Type I industries the coefficient on growth is negligible. Thus the growth variable is more important in the Type II equation which also has the higher intercept. This is consistent with the hypothesis given above.

The results for the concentration ratio variable are somewhat weak but are suggestive. This coefficient has a high degree of uncertainty in both equations. The negative sign in the Type II equation suggests that where firm size is small competition is associated with decentralization. Only among large firms of the Type I industries does Fuchs' finding of the relationship of high dispersal to high concentration appear. We don't put a great deal of faith even in this weaker version of Fuchs' position since for the Type I industries, with their large corporations, the concentration ratio is notorious for not appropriately measuring market power. This point is independent from any statistical criteria of coefficient reliability.

As expected, the water usage variable encourages the decentralization of large firms in Type I industries. For Type II industries there is no effect. Indeed the size of the coefficient is less than that of the standard error. Similarly, average plant size does not play an important role in either industry group.

\section{CONCLUSIONS}

The substantial decline of the North's manufacturing share in the postwar period is a phenomenon that has received a great deal of attention. In part this decentralization is the result of the emergence of new industries in peripheral regions. Among older industries those in the Type II group with smaller firms have shifted more rapidly than those in the Type I group with large corporations. This reflects differences in average characteristics, less than differences in sensitivity to these characteristics. This point is most easily made by dividing the average difference in decentralization between the two types of industries into that difference ascribable to different characteristics and that difference ascribable to different coefficients. Thus the average Type I industry shifted $10.3 \%$ of its value added to decentralized locations in the post-war period. The average Type II industry shifted $16.0 \%$. If the average Type I industry had determined its decentralization using the Type II equation the difference would have disappeared. Thus it is the coefficients and not the average values that account for the difference in behavior, or, alternatively, the direct and interaction effects of company size strongly dominate other differences in industry characteristics. 
These findings run counter to the hypothesis that Type I industries, like multi-national corporations, would have a faster pace of decentralization. At least in the case of the United States, the quality of the environment outside the original manufacturing belt has been more than sufficient to support numerous firms of both types. Indeed industries of the Type II variety have shown a higher propensity to decentralize.

Beyond this basic point it is clear that there are important differences in the processes that determine decentralization of the two types of industries considered here. In particular, the larger corporations of Type I industries are less sensitive to labor skill requirements, more sensitive to the wage share and more sensitive to the set of environmental requirements implied by large-scale water usage than Type II industries.

\section{FOOTNOTES}

1 Most notable in this literature are the studies of Creamer [1953, 1969], Perloff, et al. [1960] and Fuchs [1961]. The general approach taken here will be closest to Fuchs in spirit. Increasingly the issue of decentralization has been discussed in terms of its impact on the northeast. For example see Sternlieb and Hughes [1975].

2 For example see Holland Chapters 5 and 7 [1976], Hansen [1980], Erickson and Leinbach [1979].

3 For this type of argument see Holland [1976], Chapter 8.

4 The product-cycle literature is invoked by Ericksen and Leinbach [1979] among others. For the original see Vernon [1971], Chapter 3.

5 For a discussion of various empirical studies on this issue see Holland [1976], Chapter 8.

6 For example see discussion of corporate data obtained by Pred [1976].

7 At the time this paper was submitted for publication, late 1980, the 1977 census of manufactures was not yet completed. Since we wished to take a random sample of industries the study was limited to the period ending 1972.

8 We were somewhat uncertain as to an appropriate descriptive name for the two industry groups obtained in this way. While many of the industries in the "large corporate" groups are oligopolies, several had relatively modest concentration ratios. Under the circumstances "large oligopoly," the front running name, seemed misleading and the approach used in the text was adopted. As described in the text, we attempt to control separately for market power.

9 Repeating the t-test for mean differences assuming different population variances does not affect the basic result.

10 For example, Alexandersson [1967] suggests water resources have played a role in attracting chemical producers to the South.

11 For a more formal discussion of covariance analysis see Johnston [1972] pp. 192-207.

\section{REFERENCES}

ALEXANDERSSON, G. Geography of Manufacturing. Englewood Cliffs: Prentice-Hall. 1967.

CREAMER, D. Manufacturing Employment by Type of Location. New York: National Industrial Conference Board, Studies- in Business Economics, No. 106. 1969.

ERICKSON, R. AND LEINBACH, T., "Characteristics of Branch Plants Attracted to Nonmetropolitan Areas," in R. Lonsdale and H. Seyler, Nonmetropolitan Industrialization. Washington: Winston/Wiley. 1979.
FUCHS, VICTOR. Changes in the Location of Manufacturing in the U.S. Since 1929. New Haven: Yale University Press. 1961.

HANSEN, NILES, "Dualism, Capital-Labor Ratios and Regions of the U.S.: A Comment," Journal of Regional Science, August, 1980.

HOLLAND, STUART. Capital Versus The Regions. London: MacMillan Press. 1976.

PERLOFF, $\mathrm{H}$, et al. Regions, Resources and Economic Growth. Baltimore: Johns Hopkins Press. 1960 
PRED, A., "The Interurban Transmission of Growth in Advanced Economies," Regional Studies, Vol. 10, No. 2, 1976.

STERNLIEB, G. AND HUGHES, J. Post Industrial America: Metropolitan Decline and Inter-Regional
Job Shifts. New Brunswick: The Center for Urban Policy Research, Rutgers. 1975.

VERNON, RAYMOND. Sovereignty at Bay. New York: Basic Books. 1971. 


\section{APPENDIX I}

Type I Industries

\begin{tabular}{lll} 
& SIC - CODE & \\
\cline { 2 - 3 } 1972 & 1947 & 1947 Industry Name \\
\cline { 2 - 3 } 2023 & 2023 & Concentrated Milk \\
2041 & 2041 & Flour \& Meal \\
2046 & 2043 & Cereals \\
2051 & 2094 & Corn Products \\
2052 & 2051 & Bread and other Bakery Products \\
2079 & 2052 & Biscuits, Crackers \& Pretzels \\
2085 & 2079 & Shortening \& Cooking Oils \\
2087 & 2085 & Distilled Liquors \\
2812 & 2095 & Flavorings \\
2833 & 2812 & Alkalies \& Chlorine \\
2834 & 2833 & Medicinal Chemicals \\
2844 & 2834 & Pharmaceutical Preparations \\
2911 & 2893 & Toilet Preparations \\
3211 & 2911 & Petroleum Refinings \\
3221 & 3211 & Flat Glass \\
3224 & 3221 & Glass Containers \\
3231 & 3224 & Pressed \& Blown Glassware, NEC \\
3291 & 3231 & Products of Purchased Glass \\
3292 & 3291 & Abrasive Products \\
3312 & 3292 & Asbestos Products \\
3351 & $3311-2$ & Blast Furnaces \& Steel Mill \\
3411 & 3351 & Copper Rolling \& Drawing \\
3562 & 3411 & Tin Cans \& Other Tinware \\
$3613 \& 3622$ & 3593 & Ball \& Roller Bearings \\
3621 & 3616 & Electrical Control Apparatus \\
$3711 \& 37$ & 3614 & Motors \& Generators \\
3731 & 3717 & Motor Vehicles \& Parts \\
3811 & 3731 & Shipbuilding \& Repairing \\
3861 & 3811 & Scientific Instruments \\
& 3861 & Photographic Equipment \\
\hline & &
\end{tabular}


APPENDIX I (Cont'd)

Type II Industries

\begin{tabular}{lll} 
& SIC - CODE & \\
\hline 1972 & 1947 & 1947 Industry Name \\
2063 & 2063 & Beet Sugar \\
2121 & 2883 & Soybean Oil Mills \\
2254 & 2121 & Cigars \\
2284 & 2254 & Knit Underwear Mills \\
2298 & 2223 & Thread Mills \\
2327 & 2298 & Cordage \& Twine \\
2341 & 2327 & Men's \& Boys' Separate Trousers \\
2384 & 2341 & Women's \& Children's Underwear \\
2393 & 2384 & Robes \& Dressing Gowns \\
2431 & 2393 & Textile Bags \\
2491 & 2431 & Millwork Plants \\
2515 & 2491 & Wood Preserving \\
2521 & 2515 & Mattresses \& Bedsprings \\
2541 & 2521 & Wood Office Furniture \\
2643 & 2541 & Partitions \& Fixtures \\
2655 & 2661 & Paper Bags \\
2732 & 2674 & Fiber Cans, Tubes, Drums, etc. \\
2874 & 2732 & Book Printing \\
2952 & 2891 & Fertilizers \\
3021 & 2952 & Roofing Felts \& Coatings \\
3111 & 3021 & Rubber Footwear \\
3161 & 3111 & Leather Tanning \& Finishing \\
3421 & 3161 & Luggage \\
3444 & 3421 & Cutlery \\
3497 & 3444 & Sheet Metalwork \\
3533 & 3497 & Metal Foil \\
3551 & 3532 & Oilfield Machinery \& Tools \\
3586 & 3551 & Food Products Machinery \\
3623 & 3586 & Measuring \& Dispensing Pumps \\
3691 & 3617 & Electrical Welding Apparatus \\
3713 & 3691 & Storage Batteries \\
3732 & 3713 & Truck and Bus Bodies \\
3914 & 3732 & Boat Building \& Repairing \\
3955 & 3914 & Silverware \& Plated Ware \\
3262 & 3955 & Carbon Paper \& Inked Ribbons \\
3296 & 3262 & Vitreous China Food Utensils \\
3322 & 3275 & Mineral Wool \\
3341 & 3322 & Malleable Iron Foundries \\
& 3341 & Secondary Non-Ferrous Metals
\end{tabular}

